\section{Response to: Can ultrasound of the major salivary glands assess histopathological changes induced by treatment with rituximab in primary Sjögren's syndrome?}

We thank Mossel and colleagues for their interest in our work. ${ }^{12}$ They raise a number of limitations that we acknowledge and have discussed. In addition, we agree that an understanding of the pathology underlying the abnormal salivary gland ultrasound findings in Sjögren's syndrome is an important objective to help establish the validity of this tool as a potential outcome measure in clinical trials. As both we and Mossel and colleagues discuss, we did not observe a difference in hypoechoic areas between rituximab and placebo. Similar hypoechoic areas can be observed in longstanding postradiotherapy salivary glands where inflammatory cell infiltrate is variable and of a differing pattern. ${ }^{3-5}$ Furthermore, the pattern of hypoechoic areas on ultrasound in Sjögren's syndrome is reminiscent of sialography findings which are characterised by contrast-defined changes that include destructive and cavitatory stages. ${ }^{6}$ Consequently, late-stage hypoechoic lesions may reflect potentially irreversible damage rather than ongoing inflammatory lesions. However, this would not explain the reported improvement in such hypoechoic lesions following rituximab in a single-centre substudy of the French Tolerance and Efficacy of Rituximab in Primary Sjögren's Syndrome (TEARS) trial. ${ }^{7}$ Our total ultrasound score was designed some time ago, ${ }^{1}$ and prior to more recent consensus work, ${ }^{8}$ and we would not necessarily advocate this score above others for future studies. A greater number of categories for the number and sizing of hypoechoic lesions might offer greater sensitivity to change, be that an improvement or slowing of progression. However, creation of a larger yet reliable dynamic range for the measurement of hypoechoic lesions with such an operator-dependent technique, in a multicentre study, may require some form of digital image analysis. Second, we also agree that salivary gland histopathology may offer a useful window on drug efficacy or lack thereof in clinical trials in Sjögren's syndrome. We also advocate the need for standardisation and have argued that the focus score alone may be insufficient as an outcome measure, ${ }^{9} 10$ although this has yet be proved in the context of a drug that also clearly improves clinical manifestations in a double-blind multicentre study. Histology may also provide a means of predicting patients that might respond to $\mathrm{B}$ cell depleting therapies; such analyses are under way in the TRial of Anti-B-Cell Therapy In patients with primary Sjögren's Syndrome (TRACTISS) biopsy substudy and it will be interesting to see if we can replicate the reported associations between B cell infiltration and response, whether positive or negative. ${ }^{11-13}$ However, preliminary data from the ongoing histopathology analysis of TRACTISS also confirmed that no improvement in the focus score could be observed between the active and the placebo arm of the study. It will be of interest to correlate these findings with the baseline and post-treatment number and size of the hypoechoic areas observed at ultrasound. Although Mossel et al advocate the use of parotid histopathology for such repeated measures, ${ }^{2}$ data from their own group suggest that the diagnostic value of parotid and minor salivary gland histopathology is very similar, ${ }^{14}$ with the exception that lymphoepithelial lesions are more common in parotid glands compared with minor salivary glands. We would argue that minor salivary glands are far more commonly used as a routine diagnostic tool and are therefore more amenable for use in multicentre studies. Whether the reproducibility of histological measures, such as focus score, mean focus area and area of infiltration, differs between repeat biopsies of the parotid versus minor salivary glands is unknown but would help inform this debate. In conclusion, we agree with Mossel et al that further validation work on ultrasound as a potential outcome measure, and standardisation of histopathology, is both warranted and highly desirable.

\section{Benjamin A Fisher, ${ }^{1,2,3}$ Paul Emery, ${ }^{4,5}$ Costantino Pitzalis, ${ }^{6}$} Michele Bombardieri, ${ }^{6}$ Simon J Bowman ${ }^{1,2,3}$

${ }^{1}$ National Institute for Health Research (NIHR) Birmingham Biomedical Research Centre, University of Birmingham, Birmingham, UK

${ }^{2}$ Rheumatology Research Group, Institute of Inflammation and Ageing, University of Birmingham, Birmingham, UK

${ }^{3}$ Rheumatology Department, University Hospitals Birmingham NHS Foundation Trust, Birmingham, UK

${ }^{4}$ Leeds Institute of Rheumatic and Musculoskeletal Medicine, University of Leeds, Chapel Allerton Hospital, London, UK

${ }^{5}$ NIHR Leeds Biomedical Research Centre, Leeds Teaching Hospitals NHS Trust, Leeds, UK

${ }^{6}$ William Harvey Research Institute, Barts and The London School of Medicine and Dentistry, London, UK

Correspondence to Dr Benjamin A Fisher, Rheumatology Research Group, University of Birmingham, Birmingham B15 2WB, UK; b.fisher@bham.ac.uk

Handling editor Josef S Smolen

Funding The authors have not declared a specific grant for this research from any funding agency in the public, commercial or not-for-profit sectors.

Competing interests None declared.

Patient consent Not required.

Provenance and peer review Commissioned; internally peer reviewed.

(c) Article author(s) (or their employer(s) unless otherwise stated in the text of the article) 2019. All rights reserved. No commercial use is permitted unless otherwise expressly granted.

\section{Check for updates}

To cite Fisher BA, Emery P, Pitzalis C, et al. Ann Rheum Dis 2019;78:e28.

Received 29 March 2018

Accepted 29 March 2018

Published Online First 13 April 2018

\section{Sinked}

- http://dx.doi.org/10.1136/annrheumdis-2018-213332

Ann Rheum Dis 2019;78:e28. doi:10.1136/annrheumdis-2018-213340

\section{REFERENCES}

1 Fisher BA, Everett CC, Rout J, et al. Effect of rituximab on a salivary gland ultrasound score in primary Sjögren's syndrome: results of the TRACTISS randomised double-blind multicentre substudy. Ann Rheum Dis 2018:77:412-6.

2 Mossel E, Delli K, Arends S, et al. Can ultrasound of the major salivary glands assess histopathological changes induced by treatment with rituximab in primary Sjögren's syndrome? Ann Rheum Dis 2019;78:e27.

3 Cheng SC, Wu VW, Kwong DL, et al. Assessment of post-radiotherapy salivary glands. Br J Radiol 2011;84:393-402.

4 Radfar L, Sirois DA. Structural and functional injury in minipig salivary glands following fractionated exposure to 70 Gy of ionizing radiation: an animal model for human radiation-induced salivary gland injury. Oral Surg Oral Med Oral Pathol Oral Radiol Endod 2003:96:267-74.

5 Teshima K, Murakami R, Yoshida R, et al. Histopathological changes in parotid and submandibular glands of patients treated with preoperative chemoradiation therapy for oral cancer. J Radiat Res 2012;53:492-6.

6 Rubin P, Holt JF. Secretory sialography in diseases of the major salivary glands. Am J Roentgenol Radium Ther Nucl Med 1957;77:575-98.

7 Jousse-Joulin S, Devauchelle-Pensec V, Cornec D, et al. Brief report: ultrasonographic assessment of salivary gland response to rituximab in primary Sjögren's syndrome. Arthritis Rheumatol 2015;67:1623-8.

8 Jousse-Joulin S, Nowak E, Cornec D, et al. Salivary gland ultrasound abnormalities in primary Sjögren's syndrome: consensual US-SG core items definition and reliability. RMD Open 2017;3:e000364 
9 Fisher BA, Jonsson R, Daniels T, et al. Standardisation of labial salivary gland histopathology in clinical trials in primary Sjögren's syndrome. Ann Rheum Dis 2017;76:1161-8.

10 Fisher BA, Brown RM, Bowman SJ, et al. A review of salivary gland histopathology in primary Sjögren's syndrome with a focus on its potential as a clinical trials biomarker. Ann Rheum Dis 2015;74:1645-50.

11 Cornec D, Costa S, Devauchelle-Pensec V, et al. Do high numbers of salivary gland-infiltrating B cells predict better or worse outcomes after rituximab in patients with primary Sjögren's syndrome? Ann Rheum Dis 2016;75:e33.
12 Cornec D, Costa S, Devauchelle-Pensec V, et al. Blood and salivary-gland BAFF-driven B-cell hyperactivity is associated to rituximab inefficacy in primary Sjögren's syndrome. J Autoimmun 2016;67:102-10.

13 Delli K, Haacke EA, Kroese FG, et al. Towards personalised treatment in primary Sjögren's syndrome: baseline parotid histopathology predicts responsiveness to rituximab treatment. Ann Rheum Dis 2016:75:1933-8.

14 Mossel E, Delli K, van Nimwegen JF, et al. Ultrasonography of major salivary glands compared with parotid and labial gland biopsy and classification criteria in patients with clinically suspected primary Sjögren's syndrome. Ann Rheum Dis 2017;76:1883-9. 